antidepressants against active placebos but their conclusions go beyond the data, an issue I have discussed elsewhere (Anderson, 1997). They are right to be concerned about the reality of blindness in randomised controlled trials but interpretation of their results is very much a matter of opinion, particularly as there are methodological limitations in terms of the number and quality of studies they were able to analyse. This means that the actual values of the pooled effect sizes they obtained have to be regarded with great caution.

In effect, the situation is the old chestnut of whether a glass is perceived as half full or half empty. It is reassuring that antidepressants are more effective than active placebos and this study is a confirmation of their efficacy. If we do accept their effect size of about 0.4 , it is worth pointing out that this is identical to those that we found for both selective serotonin reuptake inhibitors (SSRIs) and tricyclic antidepressants (TCAs) against placebo in our meta-analysis of comparative trials which also included a placebo arm (Anderson \& Tomenson, 1994; SSRIs: 0.41 (0.32$0.50)$; TCAs: $0.40(0.31-0.50))$. In other words, studies against active placebo give results in line with those against ordinary placebo and therefore the clinical implications outlined by the authors seem to go beyond the data. There is, in fact, little evidence that active placebos provide useful additional information and so we can be reassured (although perhaps not complacent) about standard practice.

One other implication from this study is that anticholinergics themselves are unlikely to have significant antidepressant activity in support of the single negative controlled study cited by the authors.

Anderson, 1. M. \& Tomenson, B. M. (1994) The efficacy of selective serotonin reuptake inhibitors in depression: a meta-analysis of studies against tricyclic antidepressants. Journal of Psychopharmocology. 8. 238-249.

_ (1997) Psychiatry: evidence-based but still value laden. British journal of Psychiatry, 171, 226.

Moncrieff, J., Wesseley, S. \& Hardy, R. (1998) Metaanalysis of trials comparing antidepressants with active placebos. British journal of Psychiotry. 172. 227-231.

I. M. Anderson School of Psychiatry and Behavioural Sciences, University of Manchester. Rawnsley Building, Manchester Royal Infirmary. Oxford Road, Manchester MI3 9WL

\section{Aggression and violence in severe mental illness}

Sir: Scott et al (1998) recently reported results of an interview in a comparatively small community sample of people with psychosis with ( $n=27)$ and without $(n=65)$ substance misuse. Although the severity of aggression and offending among this community sample was low, individuals with a dual diagnosis were significantly more likely to report a history of committing an offence or recent hostile behaviour. Surprisingly a substantial proportion of those in the psychosis-only group reported substance-related offences, which might be explained by inadequate assessment of substance use disorders in that group.

High rates of substance misuse and dependence have been recognised as a major problem not only in the USA but also in various European samples of people with schizophrenia (Soyka et al, 1993). There is also a broad literature on the violence and delinquency of people with a dual diagnosis of substance use disorder and schizophrenia. In a subsequent analysis of the study on two large samples of people with schizophrenia (Soyka, 1993) it was shown that $25.0 \%$ of all people with schizophrenia were found to have been convicted before, basically because of offences against property $(19.5 \%)$ and traffic offences $(4.3 \%)$, whereas violent behaviour was comparatively rare $(1.8 \%)$. Patients with substance misuse had been convicted more often than people with schizophrenia and no substance misuse $(40.1$ v. $13.7 \%, P<0.001)$.

These data are in line with results of a major epidemiological study focusing on violence/aggression in schizophrenia. Lindquist \& Allebeck (1990) in a study on 644 people with schizophrenia did not find a higher crime rate among males with schizophrenia compared with the general population, but reported a four-fold higher rate of violent offences among them. Lindquist $\&$ Allebeck (1989) also demonstrated the significant role of substance misuse for assaultive behaviour in people with schizophrenia: $14(38 \%)$ of the 38 offenders with schizophrenia misused alcohol and/or drugs and seven others were probable alcohol/ drug misusers. Prevalence rates for substance misuse in violent offenders $(38 \%)$ were significantly higher than in other people with schizophrenia (16\%).

The reasons for violence and aggression among people with both schizophrenia and alcohol/drug misuse have not been fully understood. The comparatively high rate of violence and aggression in dual diagnosis schizophrenia might be explained inter alia by a more severe psychopathology, a primary antisocial personality and a more pronounced non-compliance with treatment compared with uncomplicated schizophrenia, but the possible role of intoxication should also be considered. Other epidemiological data point in that direction: Boeker \& Haefner (1973) not only found that the risk of a patient with schizophrenia acting violently was nine times higher than that of psychiatric patients with other diagnoses, they also reported that $10.4 \%$ of violent patients with schizophrenia were intoxicated at the time of their delinquent action.

In conclusion, there is broad clinical and epidemiological evidence for substance misuse being a major problem in people with schizophrenia, which has a significant impact on violence/aggression and delinquency in these patients. Implications of these findings for clinical practice and research have already been addressed by Scott et al (1998). I believe that Smith \& Hucker (1994) were also right to conclude that longitudinal studies are required to facilitate a better understanding of the inter-relationships between substance misuse and violence in schizophrenia.

Boeker, W. \& Haefner, H. (1973) Gewalttoten Geistesgestoerter. Eine Psychiatrische-Epidemiologische Untersuchung in der Bundesrepublik Deutschiand. Berlin: Springer.

Lindquist, P. \& Allebeck, P. (1989) Schizophrenia and assaultive behavior: the role of alcohol and drug abuse. Acto Psychiatrica Scondinovico, 82, $191-195$.

- (1990) Schizophrenia and crime. A longitudinal follow.up of 644 schizophrenics in Stockholm. British Journal of Psychiotry, 157, 345-350.

Scott, H., Johnson, S., Menezes, P., et ol (1998) Substance misuse and risk of aggression and offending among the severely mentally ill. British journal of Psychiotry, 172, 345-350.

Smith, J. \& Hucker, S. (1994) Schizophrenia and substance abuse. British journol of Psychiotry, 165, 13-21.

Soyka, M. (1993) Substance abuse and dependency as a risk factor for delinquency and violent behaviour in schizophrenic patients - how strong is the evidence? journal of Clinical Forensic Medicine, I. 3-7.

_. Albus, M., Finelli, A., et al (1993) Prevalence of alcohol and drug abuse in schizophrenic inpatients. European Archives of Psychiotry and Clinical Neuroscience, 242, 362-372.

M. Soyka Psychiatric Hospital, University of Munich, Nußbaumstr. 7, 80336 Munich, Germany 